\title{
Selecting a Butterfly Valve Instead of a Globe Valve for Fluid Control in a Utility Service in the Offshore Industry (Based on an Industrial Experience)
}

\author{
Karan Sotoodeh* \\ Piping Engineering, AkerSolutions, Oslo, Norway \\ *Corresponding author: karan_sqi@yahoo.com
}

\begin{abstract}
Straight pattern globe valves are widely used in the oil and gas industry to regulate and control the flow of fluids. During operation, these valves are exposed to problems such as cavitation. Cavitation happens when the pressure in a liquid suddenly drops, leaving behind a bubble of gas. There are some strategies that can be used to mitigate the risk of cavitation, such as designing the valves as per API 623 standard, selecting a different valve type such as Y-Type or axial valves, or hard facing the valve internals. These solutions increase the cost of valve selection and are more suitable for the valves in process services, such as valves containing hydrocarbon. The main question this research seeks to answer is whether a butterfly valve (e.g., wafer type) is a good replacement for a straight pattern globe valve in utility services such as water. It is noticeable that wafer type butterfly valves are much cheaper than globe valves, especially when it comes to exotic materials. 12 control valves in water services in titanium and duplex in an offshore unit were selected for research. The manual valves on the bypass of the control valves were evaluated for globe or butterfly valve selection. The data analysis included two methods of cavitation analysis and pressure drop analysis. The risk of cavitation for both butterfly and globe valves is almost the same. The analysis shows that butterfly valves are slightly more prone to cavitation risk. When it comes to pressure drop calculation analysis, none of the globe valves were suitable. On the other hand, 6 butterfly valves were suitable for the fluid control after pressure drop and cavitation analysis. In conclusion, butterfly valves are recommended for fluid control in utility services such as water.
\end{abstract}

Keywords: valve selection, cavitation, oil and gas industry, offshore

Cite This Article: Karan Sotoodeh, "Selecting a Butterfly Valve Instead of a Globe Valve for Fluid Control in a Utility Service in the Offshore Industry (Based on an Industrial Experience)." American Journal of Mechanical Engineering, vol. 6, no. 1 (2018): 27-31. doi: 10.12691/ajme-6-1-4.

\section{Introduction}

Valves are mechanical devices in a piping system that are used to direct, stop, start, mix, and regulate the flow, pressure, or temperature of the process fluid. [1] Straight pattern globe valves, widely used in the oil and gas industry, allow the flow to be regulated or controlled. The working principle of straight pattern globe valves is that flow reaches the centre of the valve where the seat and plug are located. Then the flow makes a 90-degree turn toward the seat, followed by another 90-degree turn to the outlet port, as illustrated in Figure 1.

There is a narrow area (vena contracta) in the centre of the valve where the pressure is at a minimum level and the velocity is at a maximum level. In many globe valves in liquid services, the pressure at the narrow area below the plug can drop below the vapour pressure of the liquid. When this happens, "flashing" can happen when the bubbles of the gas are vaporized from the liquid. The bubbles will recover the pressure and collapse, creating pressure waves. Consequently, the pressure waves can damage the seat, plug, and body of the globe valves. [2].
Cavitation can create irregular pits and erosion in the trim (seat and plug), the body, and downstream piping. Figure 2 shows cavitation damage in the form of small pits very similar to corrosion damage in the plugs of the globe valves. Cavitation that intensifies the effect of corrosion is called cavitation corrosion.

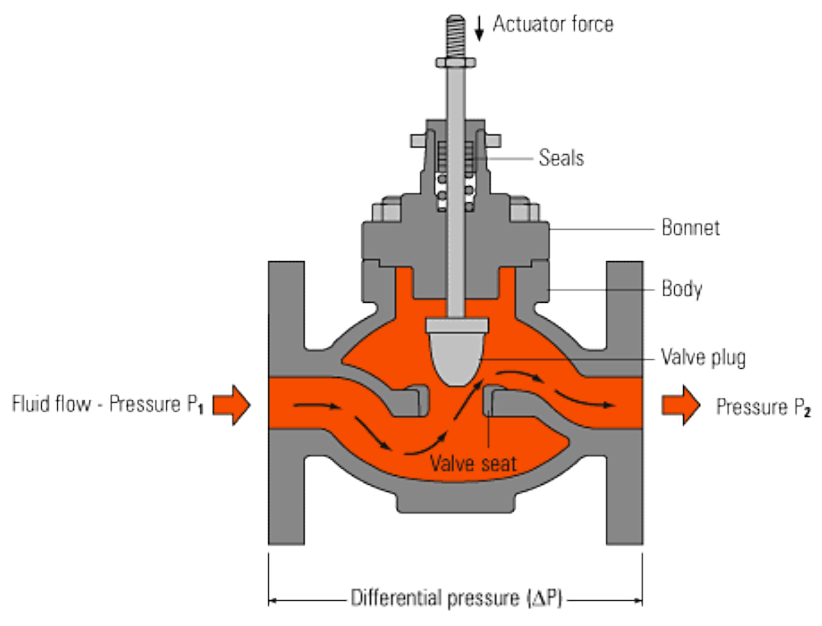

Figure 1. Flow Path in a T-pattern globe valve 


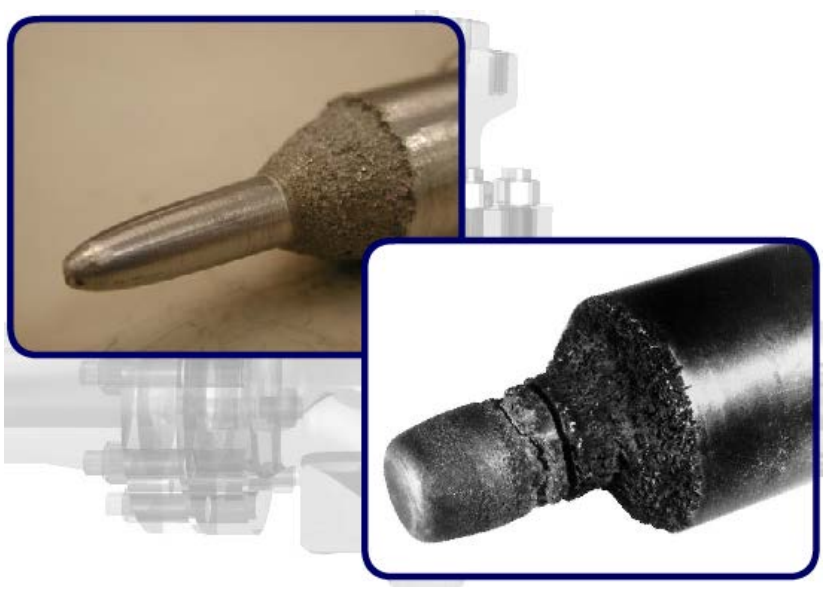

Figure 2. Cavitation Corrosion in Plugs of the globe valves

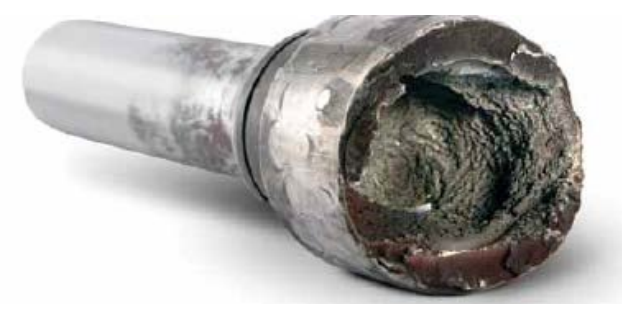

Figure 3. Cavitation damage to a globe valve plug on sealing areas

Figure 3 shows major cavitation damage in the form of pits on the plug sealing areas in a globe valve. The valve has lost its sealing capability when the plug is sitting on the seat, due to the cavitation. The bursting bubbles that cause cavitation can produce excessive noise and vibration and create localized stresses (loads) on the valve bodies in addition to pitting, corrosion, and erosion. These problems reduce the efficiency of the globe valve.

\section{Proposed Solutions}

\subsection{New Standard}

The American Petroleum Institute (API) 623 standard first edition, released in 2013, includes requirements for globe valves to avoid leakage, vibration, and cavitation. The API 623 standard specifies hard facing on both the seat and plug and the guided disk, especially for high pressure classes. The stem diameter specified in API 623 follows the principles of the API 600 Cast Steel Gate Valves Standard, with different values. The stem diameter values in API 623 are larger than other globe valve standards including BS 1873, to avoid breaks such as stem and plug separation. [3] This standard covers valves from 2" to 24” in diameter and pressure classes from 150 to 2500. Stellite is a cobalt-chromium alloy that is widely used for hard facing of the globe valve internal components including the seat and plug, to prevent erosion and cavitation.

\subsection{Alternative Valve Design \& Selection}

Y-type globe valves (see Figure 4) and axial valves (see Figure 5) are alternative valve types that can be used to avoid erosion and cavitation. A Y-type globe valve, also known as an oblique valve, is a compromise between the straight patterns and angle patterns globe valves. [4] The seat, stem and operation of a Y-type globe valve are orientated approximately $45^{\circ}$ and the flow pattern is much more streamlined compared to the straight pattern globe valve. The lower pressure loss in a Y-Type globe valve reduces the risk of wearing, erosion, and cavitation.

Axial valves are a new generation of globe valves with following advantages:

1. Low pressure drop

2. Short stroke for opening and closing in order to achieve high flow and quick closing

3. No contact between disk and seat during openingclosing stroke

4. Sealing is not directly exposed to throttling, resulting in a long life and a tight seal

5. Pressure balance disk or piston (equal pressure across the disk or piston) reduces the torque and time of opening and closing during operation of the valve

6. An axial on off valve, especially with a metal seat, can be opened against full delta $\mathrm{P}$ without any problem with socking out of the seat

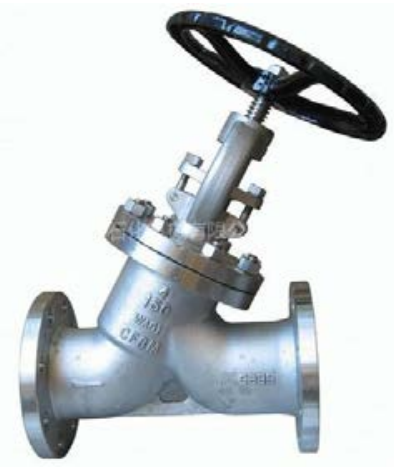

Figure 4. Y Type Globe Valve

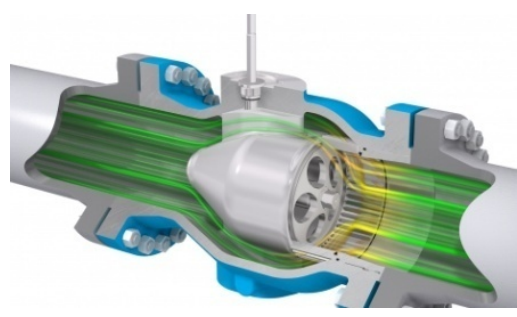

Figure 5. Axial Valve

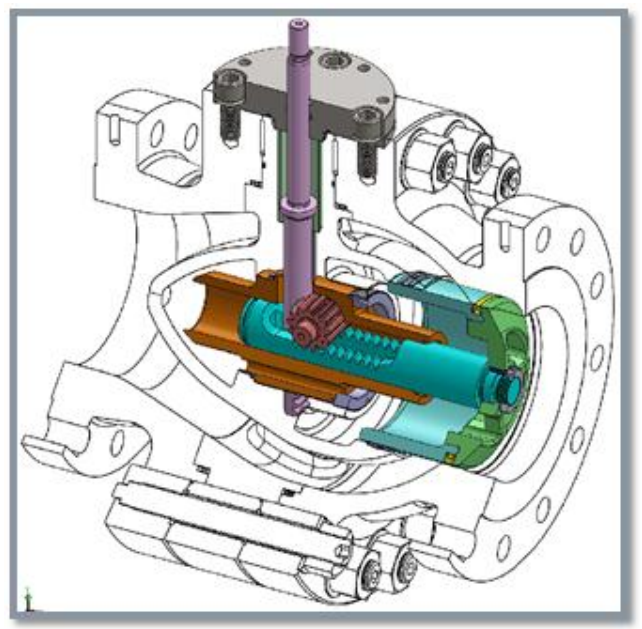

Figure 6. Axial Valve Rack and Pinion Design Developed by Goodwin 
Regarding the working principal, the valve disk slides to open or closed by means of a $90^{\circ}$ rack transmission (piston rod housing) between the piston rod and stem through teeth on both stem and the piston rod illustrated in figure 6 . The teeth have high tolerance so there is no play between valve stem and piston rod.

Y-type and axial valves are more expensive than T-type globe valves. They are recommended instead of T-type globe valves in process services for some sizes and pressure classes. Process services are those services containing hydrocarbon such as oil and gas. Cavitation risk increases with the size and pressure class, so usage of Y-type and axial valves is more common in larger and higher pressure classes in process services.

\section{Case Study \& Data Collection}

The purpose of this research is to determine what type of valve can be used instead of a T-type globe valve in utility services such as water or sea water services, Piping systems in the Norwegian offshore industry are made of exotic and expensive materials such as $25 \mathrm{Cr}$ super duplex and titanium. [5,6] Selecting an axial valve made with exotic material for sea water services increases the cost of expenditure (CAPEX) of the valves for throttling purposes. The recommendation for an end user was to select wafer-type butterfly valves (see Figure 7) instead of globe valves for utility services and fluid control application. The advantages of wafer-type butterfly valves are that they are cheaper, lighter, and more compact than globe and axial valves.
Some engineers challenge the suitability of wafer-type butterfly valves for flow control regarding their control range ability and cavitation risk. Range ability is defined as the ratio of maximum to minimum flow. [1] In some cases, wide range ability is expected from the globe valves in a fluid control application, meaning that the valve should control the flow from large to small flow amounts.

This case study analysed 12 valves. All of the valves were selected for water services (e.g. sea water, hot water, and cooling water) and located on the bypass of the control valves. Table 1 includes a list of the valves (control valves and bypass valves) as well as material and piping information. What type of valve should be selected for bypass of the control valve? Table 2 provides relevant process data received from process engineers that can be used to answer the question.

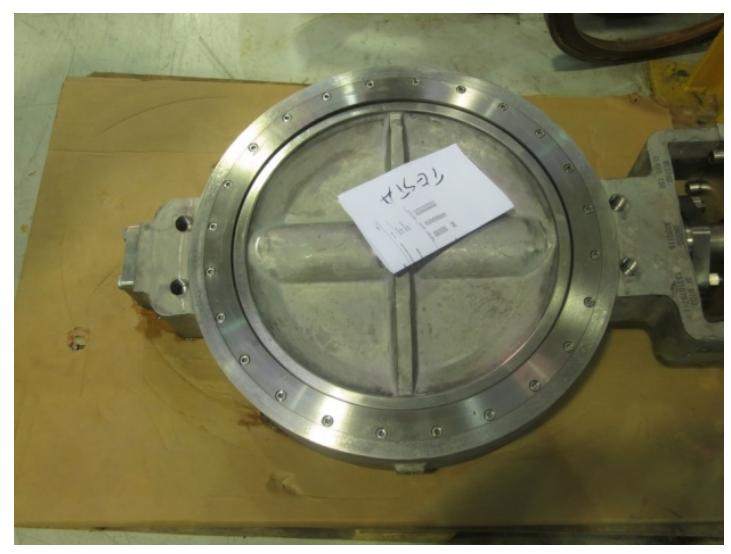

Figure 7. Wafer Type Butterfly Valve

Table 1. Control Valves \& Bypass Valves Piping Data

\begin{tabular}{|c|c|c|c|c|}
\hline Control Valve Tag Number & Bypass Valve Type & ssize (inch) & Pressure Class & Material \\
\hline 41FV0536 & Butterfly or globe valve? & $4 ”$ & 300 & 22Cr Duplex \\
\hline 41TV0275 & Butterfly or globe valve? & $6 ”$ & 300 & 22Cr Duplex \\
\hline 50FV6040 & Butterfly or globe valve? & $12 ”$ & 150 & Titanium \\
\hline 50TV0061 & Butterfly or globe valve? & $14 ”$ & 150 & Titanium \\
\hline 50PV0060 & Butterfly or globe valve? & $16 ”$ & 150 & Titanium \\
\hline 50FV6190 & Butterfly or globe valve? & $8 ”$ & 150 & Titanium \\
\hline 23TV0802 & Butterfly or globe valve? & $8 ”$ & 150 & $22 \mathrm{Cr}$ Duplex \\
\hline 23TV1392 & Butterfly or globe valve? & $8 ”$ & 150 & $22 \mathrm{Cr}$ Duplex \\
\hline 23TV1372 & Butterfly or globe valve? & $6 ”$ & 150 & $22 \mathrm{Cr}$ Duplex \\
\hline 40TV0190 & Butterfly or globe valve? & $8 ”$ & 150 & $22 \mathrm{Cr}$ Duplex \\
\hline 24TV0132 & Butterfly or lobe valve? & $10^{\prime \prime}$ & 150 & $22 \mathrm{Cr}$ Duplex \\
\hline 29TV0632 & Butterfly or globe valve? & $4 ”$ & 300 & 22Cr Duplex \\
\hline
\end{tabular}

Table 2. Control Valves \& Bypass Valves Process Data

\begin{tabular}{|c|c|c|c|c|}
\hline Control Valve Tag Number & Operating Inlet Pressure & Range of Operation & Differential Pressure & Process Comment \\
\hline 41FV0536 & 11 & $40-100 \%$ & $1-3$ & - \\
\hline 41TV0275 & 11 & $40-100 \%$ & $1-3$ & - \\
\hline 50FV6040 & 8 & $50-100 \%$ & 8 & Min.Flow \& Low accuracy \\
\hline 50TV0061 & 7,5 & $10-100 \%$ & 1 & - \\
\hline 50PV0060 & 5 & $50-100 \%$ & 4,5 & Min.Flow \& Low accuracy \\
\hline 50FV6190 & 5 & $50-100 \%$ & $2-4$ & Min.Flow \& Low accuracy \\
\hline 23TV0802 & 14 & $40-100 \%$ & 1 & High Flow \\
\hline 23TV1392 & 14 & $40-100 \%$ & 1 & High Flow \\
\hline 23TV1372 & 14 & $40-100 \%$ & 1 & High Flow \\
\hline 40TV0190 & 8 & $40-100 \%$ & 1 & High Flow \\
\hline 24TV0132 & 14 & $40-100 \%$ & $1-3$ & High Flow \\
\hline 29TV0632 & 11 & $40-100 \%$ & - \\
\hline
\end{tabular}




\section{Data Analysis \& Result}

The data analysis includes two methods of cavitation analysis [7] and pressure drop [8] analysis. The cavitation Index is calculated using the following formula:

$$
\partial=\frac{\left(P_{u}-P_{v}\right)}{\left(P_{u}-P_{d}\right)}
$$

$\partial=$ Cavity index (dimensionless)

$P_{d}=$ Downstream pressure, psig

$P_{v}=$ Vapour pressure adjusted for temperature and atmospheric pressure, psig $=-14,2$ psig for water at $60^{\circ} \mathrm{F}$, sea level

$P_{u}=$ Upstream (inlet) pressure, psig

The severity and extension of cavitation for globe valves based on cavity index values is given in Table 3. [9]

Table 3. Cavitation Severity Based on Cavity Index Values

\begin{tabular}{|l|c|}
\hline Criteria & Cavitation Consequence \\
\hline$\partial \geq 2,0$ & No Risk of Cavitation \\
\hline $1,7<\partial<2,0$ & $\begin{array}{c}\text { No cavitation control required Hardened } \\
\text { trim provides protection }\end{array}$ \\
\hline $1,5<\partial<1,7$ & Some cavitation control required \\
\hline $1,0<\partial<1,5$ & Potential for severe cavitation \\
\hline$\partial \leq 1,0$ & Flashing is occurring \\
\hline
\end{tabular}

The cavity index is calculated for the control valves as per Table 4 . The cavity indexes less than 1,5 are critical to the globe valve selection for the bypass line of the control valve. Thus, the use of globe valves as bypass valves for three valves of 50FV6040 and 50FV6190 and 50PV0060 is rejected. The second criterion provided by the end user is pressure drop analysis. A butterfly valve is a suitable valve for low pressure drop due to the fact that a globe valve creates a high pressure drop due to two times $90^{\circ}$ rotation of the fluid inside the valve. The criterion for globe valve selection is given below:

$$
0,5<\mathrm{Dp} / \mathrm{P} 1<0,7 \rightarrow \text { Globe Valve }
$$

$\mathrm{Dp} / \mathrm{P} 1$ values for the valves have been added to Table 4 regarding the $\mathrm{Dp} / \mathrm{P} 1$ values, a globe valve is not suitable for any of the cases.
Table 4. Cavitation Index Calculation Table for Globe Valves

\begin{tabular}{|c|c|c|}
\hline Control Valve Tag Number & $\begin{array}{c}\text { Cavity Index } \\
\partial\end{array}$ & Dp/P1 \\
\hline 41FV0536 & $3,99-11,98$ & $0,091-0,27$ \\
\hline 41TV0275 & $3,99-11,98$ & $0,091-0,27$ \\
\hline 50FV6040 & 1,12 & 1 \\
\hline 50TV0061 & 8,48 & 0,13 \\
\hline 50PV0060 & 1,33 & 0,9 \\
\hline 50FV6190 & $1,49-2,99$ & $0,4-0,8$ \\
\hline 23TV0802 & 14,98 & 0,07 \\
\hline 23TV1392 & 14,98 & 0,07 \\
\hline 23TV1372 & 14,98 & 0,07 \\
\hline 40TV0190 & 8,98 & 0,13 \\
\hline 24TV0132 & 4,99 & 0,21 \\
\hline 29TV0632 & $3,99-11,98$ & $0,09-0,27$ \\
\hline
\end{tabular}

Figure 8 shows the result of flow test and cavitation coefficient development for the quarter turn valves including ball, butterfly, and plug valves.[7]

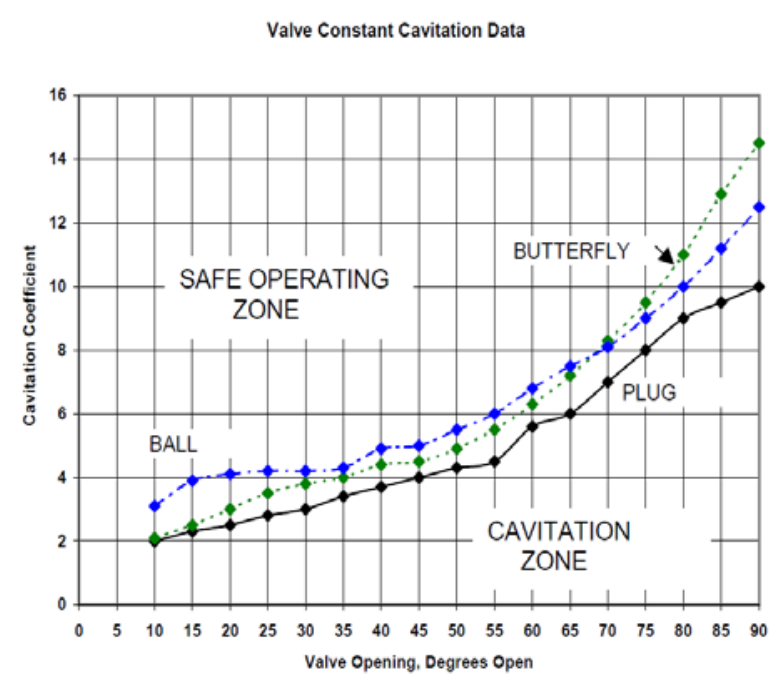

Figure 8. Cavitation Characteristic of Valves

Table 5 summarizes the cavitation risk analysis for selecting the butterfly valves on the bypass of the control valves. Less opening of the valve increases the cavity risk, so the minimum range of operation values given in Table 2 are selected for cavitation analysis.

\begin{tabular}{|c|c|c|c|c|}
\hline Control Valve Tag Number & $\begin{array}{c}\text { Cavity Index } \\
\partial\end{array}$ & Minimum Degree of Opening & $\begin{array}{l}\text { Minimum Allowable Cavity } \\
\text { Index (Figure 1) }\end{array}$ & $\mathrm{Dp} / \mathrm{P} 1$ \\
\hline 41FV0536 & 3,99-11,98 & $40 \%$ & 4,2 & $0,091-0,27$ \\
\hline $41 \mathrm{TV} 0275$ & 3,99-11,98 & $40 \%$ & 4,2 & $0,091-0,27$ \\
\hline 50FV6040 & 1,12 & $50 \%$ & 4,4 & 1 \\
\hline 50TV0061 & 8,48 & $10 \%$ & 2 & 0,133 \\
\hline 50PV0060 & 1,33 & $50 \%$ & 4,4 & 0,9 \\
\hline 50FV6190 & $1,49-2,99$ & $50 \%$ & 4,4 & $0,4-0,8$ \\
\hline 23TV0802 & 4,98 & $40 \%$ & 4,2 & 0,071 \\
\hline 23TV1392 & 4,98 & $40 \%$ & 4,2 & 0,071 \\
\hline 23TV1372 & 4,98 & $40 \%$ & 4,2 & 0,071 \\
\hline 40TV0190 & 8,98 & $40 \%$ & 4,2 & 0,125 \\
\hline 24TV0132 & 4,99 & $40 \%$ & 4,2 & 0,214 \\
\hline 29TV0632 & $3,99-11,98$ & $40 \%$ & 4,2 & $0,091-0,27$ \\
\hline
\end{tabular}

Table 5. Cavity Risk Evaluation for Butterfly Valves 
The possibility of cavitation occurring in butterfly valves is almost the same as globe valves. Similarly, three butterfly valves Like Globe Valves in Table 5 are at the risk of cavitation. In addition, three more valves, tag numbers 41FV0536, 41TV0275, and 29TV0632, are at risk of cavitation in case of butterfly valve selection, depending on the percentage of the butterfly valve opening. Therefore, only six butterfly valves can be suitable for fluid control purposes in this case study.

The next step is to check the suitability of the butterfly valves regarding the pressure drop values. The criterion for butterfly valve selection is given below:

$$
\mathrm{Dp} / \mathrm{P} 1<0 \text {, } 25 \rightarrow \text { Butterfly Valve. }
$$

One column for $\mathrm{Dp} / \mathrm{P} 1$ has been added to Table 5 to evaluate the suitability of the butterfly valves for fluid control regarding the pressure drop. The results of pressure drop analysis for butterfly valves is very similar to the results of cavity analysis. The same six butterfly valves that had been disqualified earlier are not suitable regarding pressure drop analysis. In conclusion, butterfly valves are suitable for bypass of six control valves with tag numbers 50TV0061, 23TV0802, 23TV1392, 23TV1372, 40TV0190, and 24TV0132.

\section{Conclusions \& Recommendations}

Straight pattern globe valves that are used in the oil and gas industry are at high risk of cavitation during fluid control operations. For this reason a relatively new standard, API 623, was created to design a more robust straight pattern globe valve by hard facing the valve internals, creating a stronger connection between stem and disk, and other solutions. Alternatively, more expensive valves such as Y-type globe and axial valves can be used for fluid control in process services such as hydrocarbon. The primary purpose of this research was to determine whether a butterfly valve (e.g., wafer type) can be used successfully instead of a globe valve for utility services such as water. Twelve control valves in utility services, primarily water, in an offshore project were selected for this study. Manual valves on the bypass of these 12 control valves were evaluated for cavitation and pressure drop analyses to determine the correct valve type selection. The cavitation analysis showed that the risk of cavitation is almost equal in both butterfly and straight pattern globe valves. Neither butterfly valve nor globe valves are suitable for bypass of the control valves with tag numbers 50FV6040, 50PV0060, and 50FV6190. The analysis showed very low risk of butterfly valve for bypass of the control valves with tag numbers of 41FV0536, 41TV0275, and 29TV0632. However, selecting the straight pattern globes valve for the bypass of the three mentioned tags is not risky regarding cavitation. The pressure drop analysis shows that globe valves are not suitable for any of 12 cases. But a butterfly valve can be selected for bypass of the six control valves. It was concluded during the pressure drop analysis that butterfly valves can be more suitable than globe valves in utility services. In addition, butterfly valves are much cheaper than globe valves, especially when manufactured in exotic materials such as titanium and duplex.

\section{References}

[1] Skousen P.L. (2004). Valve Handbook, $3^{\text {rd }}$ Edition. New York, NY: McGraw-Hill.

[2] Sotoodeh K. (2016). Cavitation in Globe Valves and Solutions. Valve World Magazine, 21(03), pp.32-36.

[3] Merrick R. (2015). Globe Valves-A New Standard, Valve World Conference, Asia, China, Suzhou.

[4] Nesbitt B. (2007). Handbook of Valves and Actuators: Valves Manual International, $1^{\text {st }}$ Edition. Oxford, UK: Elsevier.

[5] Norwegian Oil and Gas Standard (NORSOK) (2014). NORSOK M-001, Material Selection, 5th edition. Lysaker, Norway.

[6] Norwegian Oil and Gas Standard (NORSOK), (1999). NORSOK L-001, Piping and Valves. $3^{\text {rd }}$ revision. Lysaker, Norway.

[7] Val-Matic Valve And Manufacturing Corp. (2008). Cavitation in Valves.Retrieved from http://www.valmatic.com/pdfs/Cavitation_in_Valves_7-22-08.pdf.

[8] Statoil. (2015). Valve Selection Manual-Control Valves. $2^{\text {nd }}$ Edition. Oslo, Norway.

[9] Flowserve. (2006). Flowserve Cavitation Control .Retrieved from http://www.imaha.cz/media/files/shop/microcav.pdf. 